\title{
Preparation, Phase Equilibria, and Crystal Chemistry of Lanthanum, Praseodymium, and Neodymium Hydroxide Chlorides
}

\author{
EDWARD THEODORE LANCE AND JOHN M. HASCHKE* \\ Department of Chemistry, University of Michigan, Ann Arbor, Michigan 48109
}

Received May 6, 1975; in revised form, August 8, 1975

\begin{abstract}
The preparation of hydroxide chlorides of lanthanum, praseodymium, and neodymium has been achieved by hydrothermal methods at $550 \mathrm{C}$ and $1530 \mathrm{~atm}$. Three phases $\left(\operatorname{Ln}(\mathrm{OH})_{3}, \operatorname{Ln}(\mathrm{OH})_{2.55^{-}}\right.$ $\mathrm{Cl}_{0 .+5}$, and $\left.\ln (\mathrm{OH})_{2} \mathrm{Cl}\right)$ have been characterized hy analytical and $\mathrm{X}$-ray methods. The observed compositions are closely defined by the $x=0,0.5$, and 1 members of the homologous anion substituion series, $L n(\mathrm{OH})_{3-x} \mathrm{Cl}_{x}$. The previously unreported $L n(\mathrm{OH})_{2.55} \mathrm{Cl}_{0.45}$ phases are clearly substoichiometric in chloride and are described by the $L_{7}(\mathrm{OH})_{18} \mathrm{Cl}_{3}$ composition. X-ray diffraction data for the phases at $x=0.45$ show a pronounced $\mathrm{UCl}_{3}$-type substructure and complex superstructure reflections that have been indexed on a hexagonal cell. For the lanthanum phase, $a=17.662(6)$ and $c=3.914(1) \AA$. Efforts to obtain single crystals have been unsuccessful. Thermal decomposition processes of the hydroxide chlorides have been investigated, and the characterization of $\mathrm{LaO}(\mathrm{OH})$ ${ }_{0.55} \mathrm{Cl}_{1.45}$, a monoclinic YOOH-type intermediate phase, is reported. Suructural features and phase equilibria of the hydroxide chlorides are discussed and analogies with the hydroxide nitrate systems are drawn.
\end{abstract}

\section{Introduction}

The hydrothermal chemistry of several lanthanide + hydroxide + monovalent anion systems $\left(\mathrm{Ln}^{3+}+\mathrm{OH}^{-}+\mathrm{X}^{-} ; \mathrm{X}^{-}=\mathrm{F}^{-}, \mathrm{Cl}^{-}\right.$, $\left.\mathrm{NO}_{3}{ }^{-}\right)$have recently been described $(1-5)$. Wide regions of solid solution have been reported for the hydroxide fluoride systems $(1,2)$, but an initial study of the praseodymium hydroxide nitrate system (4) has shown the presence of two-phase regions and the possible existence of an anion substitution series, $\operatorname{Ln}(\mathrm{OH})_{3-x}\left(\mathrm{NO}_{3}\right)_{x}(x=0,0.5,1)$, with structural similarities between the series members. Subsequent investigation of lanthanide hydroxide nitrate systems (5) has confirmed these findings, but indicates a pronounced substoichiometry in nitrate content for the phases near $x=0.5$. Single crystal X-ray structures for the dimorphic forms of $\mathrm{La}(\mathrm{OH})_{2} \mathrm{NO}_{3}(6,7)$ show that their struc-

* To whom all correspondence should be addressed. Copyright 1976 by Academic Press, Inc. All rights of reproduction in any form reserved. Printed in Great Britian tures are readily described by alternating layers of $\operatorname{Ln}(\mathrm{OH})_{2}{ }^{+}$and $X^{-}$and may be derived from parent $\mathrm{UCl}_{3}$-type or $\mathrm{PuBr}_{3}$-type structures. These correlations have contributed to a general interpretation of phase equilibria, anion substitution, and crystal chemistry in metal (III) + monovalent anion systems of the lanthanides and actinides (8). Anion substitution processes which give hydroxide nitrate phases near $x=0.5$ have been proposed (8), but structural data are required for adequate understanding of the crystal-chemical relationships. Difficulties with twinning and disorder of the hydroxide nitrates $(4,6)$ suggest that investigation of other monovalent anion systems might be more productive.

Consideration of possible anion systems suggests that a monatomic ion such as chloride might be a suitable substitute for nitrate. Although structures of the $\operatorname{Ln}(\mathrm{OH})_{2} \mathrm{Cl}$ phases $(x=1)$ have been thoroughly investigated $(3,9,10)$, the hydrothermal chemistry and 
phase equilibria in these systems have not been reported. The chloride systems are of particular interest because they might show wide miscibility ranges like those of the fluorides, or the existence of a homologous anion substitution series, $\operatorname{Ln}(\mathrm{OH})_{3-x} \mathrm{Cl}_{x}$, like the nitrates. In an effort to define these systems and enhance the understanding of the crystal chemistry and anion substitution processes in monovalent anion systems, the present investigation was undertaken.

\section{Experimental}

The lanthanide ( $L n=\mathrm{La}, \mathrm{Pr}, \mathrm{Nd})$ hydroxide chlorides were prepared by hydrothermal reaction of the oxide and hydrated chloride according to

$$
\begin{aligned}
& (3-x) \operatorname{LnO}_{1.5}+x \operatorname{LnCl}_{3} \cdot y \mathrm{H}_{2} \mathrm{O} \\
& \quad \stackrel{\left(\mathrm{H}_{2} \mathrm{O}\right)}{\longrightarrow} 3 \operatorname{Ln}(\mathrm{OH})_{3-x} \mathrm{Cl}_{x}+(x y+1.5 x \\
& \quad-4.5) \mathrm{H}_{2} \mathrm{O} .
\end{aligned}
$$

Mixtures $(0.2-1.0 \mathrm{~g})$ of the calcined oxide $(99.9 \%$ or higher purity, American Potash and Chemical Corp.) and respective hydrated chloride were prepared in the composition range $0 \leqslant x \leqslant 1.5$, welded in gold capsules (4.5 $\mathrm{mm}$ i.d., $20-40 \mathrm{~mm}$ long), and reacted in cold-seal pressure vessels (4) at $550 \pm 50^{\circ} \mathrm{C}$ and $1530 \pm 35 \mathrm{~atm}$ for 3 to 5 days. For praseodymium, the trihydroxide was first prepared by hydrothermal reaction of $\mathrm{PrO}_{1.833}$ (Research Chemicals) with water and subsequently reacted with the hydrated chloride. The hydrated chlorides were obtained by dissolving the oxides in excess hydrochloric acid (reagent grade) and evaporating the solution to dryness. After the reactors were cooled slowly $(1-2 \mathrm{hr})$ to room temperature, the products were removed, washed with water and acetone and dried in air.

The products were characterized by X-ray diffraction and chemical analysis. Powder $X$-ray diffraction data were obtained with a 114.6-mm diameter Haegg-type Guinier camera using $C u K \alpha_{1}$ radiation and silicon $\left(a_{0}=\right.$ $5.43062 \AA$ ) as an internal standard. Compositions of crystallographically pure products were determined by chemical analysis. Metal contents were determined gravimetrically by dissolution of the products in nitric acid, precipitation of the oxalate, and ignition to the oxide. The chloride contents were determined by a gravimetric silver chloride procedure. Gravimetric analyses for hydroxide contents were effected by pyrolysis of samples under dry nitrogen and collection of product water on anhydrous magnesium perchlorate. The final values were obtained by difference.

Crystal growth experiments were conducted for the lanthanum phases using several mineralizing agents $\left(4 \mathrm{M} \mathrm{NH}{ }_{4} \mathrm{Cl}, 6 \mathrm{M} \mathrm{NH} \mathrm{NH}_{4} \mathrm{Cl}\right.$, $4 \mathrm{MNH}_{4} \mathrm{NO}_{3}$, plus $2: 1,1: 1$, and $1: 2.25 \mathrm{mix}-$ tures of $6 \mathrm{M} \mathrm{NH} \mathrm{NH}_{4} \mathrm{Cl}$ and $4 \mathrm{M} \mathrm{NH}_{4} \mathrm{NO}_{3}$ ) at $500^{\circ} \mathrm{C}$ and $1150 \mathrm{~atm}$ or $700^{\circ} \mathrm{C}$ and 1530 atm for reaction periods of up to 4 weeks.

Thermal decomposition reactions of the hydroxide chlorides were examined with a Perkin-Elmer TGS-1 thermobalance. Samples $(5-10 \mathrm{mg})$ were pyrolyzed in a Pt boat under flowing dry nitrogen at temperatures up to $800^{\circ} \mathrm{C}$ and heating rate of $2.5^{\circ} \mathrm{min}^{-1}$. Intermediate thermal decomposition products were prepared by heating larger samples $(0.1$ $0.25 \mathrm{~g})$ under dry nitrogen at selected constant temperatures in a tube furnace.

\section{Results}

The products were polycrystalline solids with the characteristic colors of the respective lanthanides. X-ray data for samples in the composition range $0 \leqslant x \leqslant 1.5$ indicated phases at $x=0,1$, and near 0.5 . The coexistence of two condensed phases was observed for $0<x<0.5$ and $0.5 \leqslant x<1$. For $x>1$, the $x=1$ product, $\operatorname{Ln}(\mathrm{OH})_{2} \mathrm{Cl}$, was the only solid phase. X-ray diffraction data for products at the $x=0.5$ composition showed the presence of trace quantities of the $x=1$ product. The composition of the lanthanum phase was determined from metal and halide analyses to be $\mathrm{La}(\mathrm{OH})_{2.55 \pm 0.03} \mathrm{Cl}_{0.45 \pm 0.01}$ (found La, $69.56 \pm$ $0.43 \% ; \mathrm{Cl}, 8.00 \pm 0.07 \%$; theoretical La, $70.07 \% ; \mathrm{Cl} 8.05 \%$ ).

Powder X-ray diffraction data for the hexagonal $\mathrm{UCl}_{3}$-type trihydroxide $(x=0)$ and monoclinic $\mathrm{Y}(\mathrm{OH})_{2} \mathrm{Cl}$-type dihydroxide monochlorides $(x=1)$ correspond closely with previously reported values $(3,9-11)$. 
$X$-ray data for the phases near $x=0.5$ show a pronounced superstructure-substructure relationship. The strong substructure reflections are indexable in a hexagonal system and indicate the existence of a $\mathrm{UCl}_{3}$-type sublattice. The refined substructure parameters presented in Table $\mathbf{I}$ are consistent with the substoichio- metric compositions obtained by chemical analysis. Vegard's law graphs for the $\mathrm{UCl}_{3}$ type $\operatorname{Ln}(\mathrm{OH})_{3-x} \mathrm{Cl}_{x}$ systems $(\mathrm{Ln}=\mathrm{La}, \mathrm{Pr}, \mathrm{Nd})$ all indicate compositions in the range $0.4<x<0.45$. The weaker superstructure reflections have been indexed on a hexagonal system by comparison of the data with those

TABLE I

Refined Lattice Parameters of the $L n(\mathrm{OH})_{2.55} \mathrm{Cl}_{0.45}$ Phases $^{a}$

\begin{tabular}{ccccc} 
& \multicolumn{2}{c}{ Subcell parameters $(\AA)$} & \multicolumn{2}{c}{ Lattice parameters $(\AA)$} \\
\cline { 2 - 4 }$L$ & \multicolumn{1}{c}{$a$} & $c$ & $a$ & $c$ \\
$\mathrm{La}$ & $6.676(2)$ & & & \\
$\mathrm{Pr}$ & $6.60(1)$ & $3.914(1)$ & $17.662(6)$ & $3.914(1)$ \\
$\mathrm{Nd}$ & $6.573(4)$ & $3.825(2)$ & $17.46(1)$ & $3.823(2)$ \\
\end{tabular}

${ }^{a}$ Uncertainties in last digit appear in parentheses.

TABLE II

Powder X-Ray Diffraction Data fOR La $(\mathrm{OH})_{2.55} \mathrm{Cl}_{0.45}{ }^{a}$

\begin{tabular}{|c|c|c|c|c|}
\hline Rel I & $d_{\mathrm{obs}}(\AA)$ & $d_{\text {cal }}(\AA)$ & $\begin{array}{c}h k / \\
\left(\mathrm{UCl}_{3} \text {-type subcell }\right)\end{array}$ & $\begin{array}{c}h k / \\
\text { (hexagonal supercell) }\end{array}$ \\
\hline$w$ & 7.715 & 7.648 & & 200 \\
\hline s & 5.805 & 5.781 & 100 & 210 \\
\hline vw & 4.251 & 4.242 & & 310 \\
\hline$w$ & 3.828 & 3.824 & & 400 \\
\hline $\mathrm{m}$ & 3.512 & 3.509 & & 320 \\
\hline$s$ & 3.339 & 3.338 & 110 & 410 \\
\hline vs & 3.241 & 3.241 & 101 & 211 \\
\hline$w$ & 3.106 & 3.105 & & 301 \\
\hline$w$ & 3.053 & 3.059 & & 500 \\
\hline $\mathrm{m}$ & 2.920 & 2.929 & 200 & 221 \\
\hline $\mathrm{m}$ & 2.876 & 2.877 & & 311 \\
\hline $\mathrm{m}$ & 2.747 & 2.747 & & 510 \\
\hline$w$ & 2.732 & 2.735 & & 401 \\
\hline $\mathrm{m}$ & 2.612 & 2.613 & & 321 \\
\hline $\mathrm{m}$ & 2.538 & 2.540 & 111 & 411 \\
\hline$m$ & 2.512 & 2.516 & & 430 \\
\hline $\mathrm{m}$ & 2.446 & 2.449 & & 520 \\
\hline $\mathrm{m}$ & 2.340 & 2.352 & & 331 \\
\hline $\mathrm{s}$ & 2.326 & 2.325 & 201 & 421 \\
\hline $\mathrm{m}$ & 2.252 & 2.249 & & 511 \\
\hline $\mathrm{m}$ & 2.186 & 2.185 & 210 & 700 \\
\hline$w$ & 2.138 & 2.136 & & 601 \\
\hline
\end{tabular}

${ }^{a} \mathrm{~s}=$ strong; $\mathrm{m}=$ medium; $\mathrm{w}=$ weak $\mathrm{v}=$ very. 
of the corresponding lanthanide nitrates, $\mathrm{Ln}(\mathrm{OH})_{3-x}\left(\mathrm{NO}_{3}\right)_{x}(x=0.43 \pm 0.03)$ (5). The refined lattice parameters also appear in Table $I$, and the diffraction data for the lanthanum phase are presented in Table II.

Thermal decomposition reactions of the lanthanum and ncodymium hydroxide chlorides have been obtained from $t g$ data. The twostep decomposition observed for the $\ln (\mathrm{OH})_{2.55} \mathrm{Cl}_{0.45}$ phase is demonstrated by the $t g$ curve for the lanthanum compound (Fig. 1) and described by the reaction

$$
\begin{aligned}
& \operatorname{Ln}(\mathrm{OH})_{2.55} \mathrm{Cl}_{0.45} \rightarrow \operatorname{LnO}(\mathrm{OH})_{0.55} \mathrm{Cl}_{0.45} \\
& \quad+\mathrm{H}_{2} \mathrm{O}(\mathrm{g}) \rightarrow 0.55 L n \mathrm{O}_{1.5}+0.45 L n \mathrm{OCl} \\
& \quad+0.275 \mathrm{H}_{2} \mathrm{O}(\mathrm{g}) .
\end{aligned}
$$

The arrows in Fig. 1 define the theoretical mass losses calculated for Eq. (2). X-ray diffraction data indicate that the only solid products are $L_{2} \mathrm{O}_{3}$ and $L n \mathrm{OCl}$, but the mass losses in Fig. 1 deviate noticeably from the theoretical values. These differences apparently arise from the formation of hydrogen chloride, which increases the ratio of oxide to oxide chloride in the residue. Analysis of the solid pyrolysis products showed lower $\mathrm{Cl}: \mathrm{La}$ ratios than those of the original samples. The consistently low and irreproducible water analyses observed for the intermediate hy-

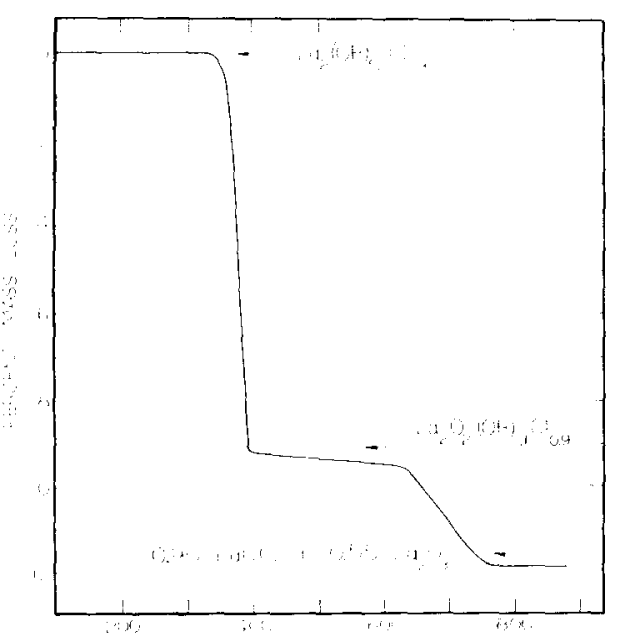

Fig, 1. Thermal decomposition curve for La$(\mathrm{OH})_{2.55} \mathrm{Cl}_{0.45}$. droxide chlorides are also consistent with the loss of hydrogen as $\mathrm{HCl}$ at elevated temperatures. The $t g$ curves obtained for a sample of finely ground $\mathrm{I} a(\mathrm{OH})_{2} \mathrm{Cl}$ crystals showed a single mass loss to $\mathrm{LaOCl}$. The decomposition temperature $\left(350-375^{\circ} \mathrm{C}\right)$, which is markedly lower than that $\left(420^{\circ} \mathrm{C}\right)$ reported previously (12), may result from differences in heating rate or atmosphere.

Pyrolysis of $\mathrm{La}(\mathrm{OH})_{2.55} \mathrm{Cl}_{0.45}$ at $320^{\circ} \mathrm{C}$ produced the intermediate phase in sufficient quantities for chemical and X-ray analysis. Within experimental error, the observed mass losses were equal to the theoretical values; elemental analysis show the composition $\mathrm{LaO}(\mathrm{OH})_{0.55} \mathrm{Cl}_{0.45}$ (found $8.74 \% \mathrm{Cl}$; theoretical $8.85 \% \mathrm{Cl}$ ). The $\mathrm{X}$-ray diffraction data have been indexed on a monoclinic $\mathrm{YOOH}$-type structure (13). The refined lattice parameters are $a=6.99(4) \AA, b=4.06(4) \AA, r=4.46(3) \AA$, $\beta=114.3(9)^{\circ}$.

Although large crystals of the $\operatorname{Ln}(\mathrm{OH})_{2} \mathrm{Cl}$ phases are readily formed during the preparative procedures, all attempts to grow single crystals of $\mathrm{La}(\mathrm{OH})_{2.55} \mathrm{Cl}_{0.45}$ were unsuccessful. A slight coarsening of the product was observed with aqueous media, but the use of $\mathrm{NH}_{4} \mathrm{Cl}$ and $\mathrm{NH}_{4} \mathrm{NO}_{3}$ mineralizer solutions only produced crystals of $\mathrm{La}(\mathrm{OH})_{2} \mathrm{Cl}$ and $\mathrm{La}(\mathrm{OH})_{2.57}\left(\mathrm{NO}_{3}\right)_{0.43}(3)$, respectively.

\section{Discussion}

A close correspondence is apparent for the hydroxide nitrate (5) and hydroxide chloride phases of the lighter lanthanides. Both systems exhibit anion substitution phases, $\operatorname{Ln}_{x}(\mathrm{OH})_{3-x^{-}}$ $X_{x}$, with narrow compositions at $x=0$, $x \simeq 0.45$, and $x=1$. At $500^{\circ} \mathrm{C}$, the hydroxide chlorides do not show broad miscibility ranges like those of the hydroxide fluorides $(I, 2)$.

The structures of the hydroxide chlorides and hydroxide nitrates are similar and consistent with the concept of anion substitution into the parent trihydroxide structures. The monoclinic $\mathrm{Y}(\mathrm{OH})_{2} \mathrm{Cl}$-type structure is easily derived from the structure of the hexagonal trihydroxide (8). The $\mathrm{UCl}_{3}$-type hydroxides are described by alternating layers of $\mathrm{La}(\mathrm{OH})_{2}{ }^{+}$ and $\mathrm{OH}^{-}$, which lie parallel to (1010). The $\operatorname{Ln}(\mathrm{OH})_{2} \mathrm{Cl}$ composition is attained by com- 
plete replacement of $\mathrm{OH}^{-}$by $\mathrm{Cl}^{-}$in the anion layers. The monoclinic structure is derived by translational shear parallel to layers, i.e., shear along [10T0] of the hexagonal structure. The ensuing reduction in metal coordination from nine- to eightfold is consistent with radius ratio effects of chloride substitution. The structure of the monoclinic $\operatorname{Ln}(\mathrm{OH})_{2} \mathrm{NO}_{3}$ phases (5) has recently been determined (7) and is very similar to that of the $\mathrm{Y}(\mathrm{OH})_{2} \mathrm{Cl}$ type structures. Because of the geometry of the nitrate ion, the metals remain nine-coordinate in the hydroxide nitrate structure.

A maximum value of $x=1$ is observed for both the nitrate and chloride systems. For $x>1$, anion substitution destroys the integrity of the infinite $\operatorname{Ln}(\mathrm{OH})_{2}{ }^{+}$layers. In the absence of a $\operatorname{Ln}(\mathrm{OH})_{2}{ }^{+}$backbone, higher members of the substitution series are soluble in the aqueous phase and are unobserved.

The results indicate that the hydroxide chloride phases at $x=0.45$ and their nitrate analogs (5) are apparently isostructural. This assignment is consistent with the observation of a similar, but less pronounced hexagonal substructure for $\operatorname{Pr}(\mathrm{OH})_{2.57}\left(\mathrm{NO}_{3}\right)_{0.43}$ (4) and is supported by the close agreement of the calculated and observed $d$ values in Table II. Theoretical considerations require that the space group of the superstructure be the same as that of the substructure $\left(P 6_{3} / \mathrm{m}\right)$ or a subgroup of that spacegroup $(14-16)$. The observed systematic absences for both the hydroxide nitrate (5) and the hydroxide chloride are consistent with space group $P 6_{3} / \mathrm{m}$ or $P 6_{3}$ and provide additional support for the proposed indexing.

It is interesting to consider the rather unusual compositions of the $\operatorname{Ln}(\mathrm{OH})_{2.55} \mathrm{Cl}_{0.45}$ phases in light of preliminary crystallographic data for $\mathrm{La}(\mathrm{OH})_{2.57}\left(\mathrm{NO}_{3}\right)_{0.43}$. X-ray singlecrystal results (I7) have shown that $Z=14$ and that the empirical formula is $\mathrm{La}_{7}(\mathrm{OH})_{18^{-}}$ $\left(\mathrm{NO}_{3}\right)_{3}$. The corresponding theoretical composition for the hydroxide chloride, $\mathrm{La}(\mathrm{OH})$ ${ }_{2.571} \mathrm{Cl}_{0.429}$, agrees well with the experimental value. The chloride ions apparently occupy an ordered arrangement of hydroxide positions, but the relationship to the layered structures and the proposed anion substitution model $(8)$ is not known.
The loss of water by the $\operatorname{Ln}(\mathrm{OH})_{2} \mathrm{Cl}$ and $\operatorname{Ln}(\mathrm{OH})_{2.55} \mathrm{Cl}_{0.45}$ phases in one- and two-step process, respectively, seems somewhat inconsistent. Formation of the intermediate $\mathrm{LnO}(\mathrm{OH})_{0.55} \mathrm{Cl}_{0.45}$ compositions may be determined by the thermodynamic stability of the YOOH-type structure, or by favorable kinetics associated with the facile interconversion of $\mathrm{UCl}_{3^{-}}$and $\mathrm{YOOH}$-type structures (8). The metal ion positions are essentially unchanged by dehydration of the trihydroxide. Formation of I.nOOH compositions and YOOH-type structures during pyrolysis of the trihydroxides can be achieved by removal of all $\mathrm{OH}^{-}$ions from the intervening anion layers, conversion of half of the $\mathrm{OH}^{-}$ions in the $\mathrm{Ln}(\mathrm{OH})_{2}{ }^{+}$layers to $\mathrm{O}^{2-}$, and collapse of the resultant $\mathrm{LnOOH}$ layers. Since the substructure of the intermediate hydroxide chloride is also $\mathrm{UCl}_{3}$-type, an analogous decomposition process presumably occurs. The $\operatorname{Ln}(\mathrm{OH})_{2.57^{-}}$ $\left(\mathrm{NO}_{3}\right)_{0.43}$ phases $(\mathrm{L} n=\mathrm{La}-\mathrm{Nd})$ also pyrolyze to form the corresponding oxide hydroxide nitrates, but the YOOH-type structures are not observed (5).

A close correspondence between the hydroxide chloride and hydroxide nitrate systems of the lighter lanthanides has been found. A discontinuity in the structural features and compositions of the intermediate hydroxide nitrates occurs between neodymium and samarium (5). A similar situation exists for the hydroxide chloride systems, and an investigation of the phase equilibria and structural properties of the hydroxide chlorides of the heavier lanthanides is in progress. Although attempts to obtain single crystals of the intermediate phases and to elucidate their structural features have not been successful, ellorts to further characterize these and other materials are continuing.

\section{Acknowledgment}

The financial support of a Research Corp. Cottrell Grant is gratefully acknowledged. The help of Dr. $\mathrm{J}$. J. Bartel in obtaining $t g$ data is greatly appreciated.

\section{References}

I. A. Marbeur, G. Demazfau, S. Turkell, P. Hagenmuller, J. Derouft, ani) P. Caro, J. Solid State Chem. 3. 637 (1971). 
2. J. M. HASCHKE, J. Solid State Chem. 12, 115 (1975).

3. F. L. Cakter and S. Levinson, Inorg. Chem. 8 , 2788 (1969).

4. J. M. Haschke and L. Eyring, Inorg. Chem. 10, 2267 (1971).

5. J. M. HASCHKE, Inorg. Chem. 13, 1812 (1974).

6. J. M. Haschke, L. R. Wyles, T. A. Deline, and D. R. PEACOR, Proc. Eleventh Rare Earth Research Conf., AEC Report CONF741002-P2, Traverse City, Mich., Oct. 1974, p. 550.

7. M. LUNDBERG, private communication, Arizona State University.

8. J. M. Haschke, J. Solid State Chem. 14, 238 (1975).

9. K. Dornberger-Schiff and R. F. Klevtsova, Acta. Crystallogr. 22, 435 (1974).

10. P. V. Klevtsov, L. Yukharchenko, 1. G. Lysenina, and Z. A. Gronkina, Zh. Neorg. Khim. 17, 2880 (1972).
11. G. Brauer, in "Progress in Science and Technology of the Rare Earths," (L. Eyring, Ed.), Vol. 3, p. 434. Pergamon Press, New York.

12. N. Demyanets, V. I. Bukin, E. N. Emfl'yanova, AND V. I. IvanOV, Kristallografiya 18, 1283 (1973); Sov. Phys. Crystallogr. 18, 806 (1974).

13. A. N. Christensen, Acta. Chem. Scand. 19, 1391 (1965).

14. M. J. Buerger, J. Chem. Phys. 15, 1 (1947).

15. J. NeubüSER AND H. WoNdRATSCHEK, Kristall und Technik 1, 531 (1966).

16. H. WONDRATSCHEK, "Tables for Maximal Subgroups and Supergroups of the Space Groups," private communication.

17. R. M. Alway, D. R. Peacor, and J. M. Haschkf, unpublished results. 